\title{
QU
}

\section{O SHOW ATÔMICO : JOGO DIDÁTICO COMO FERRAMENTA NO PROCESSO DE ENSINO E APRENDIZAGEM DE ESTRUTURA ATÔMICA}

CAVALCANTE, J. M.L. (IFRN), CRUZ, K.C.A.D (EEPAD), FERNANDES, P. R. N. (IFRN), BERTINI, L. M. (IFRN), ALVES, L. A. (IFRN), GURGEL, A. O. (IFRN)

\section{RESUMO}

Atualmente, busca-se no ensino de Química do ensino médio, um ensino mais interativo, mais dinâmico, e que desperte interesse nos alunos. Partindo disso, os professores trazem novas metodologias de ensino para sala de aula, uma grande proposta são os jogos didáticos. Pensando nisso, o referente artigo tem como objetivo verificar as contribuições do jogo Show Atômico para os alunos da 1 a série do ensino médio noturno da Escola
Antônio Dantas no município de Apodi-RN. Durante a aplicação do mesmo, os alunos interagiram mais em sala de aula, e com base em um questionário, os mesmos aprovaram o lúdico aplicado e recomendaram mais aplicações de jogos didáticos em sala de aula.

\section{THE ATOMIC SHOW : EDUCATIONAL GAME AS A TOOL IN THE PROCESS OF TEACHING AND LEARNING ATOMIC STRUCTURE}

\begin{abstract}
Currently, search is in high school chemistry teaching, a more interactive teaching, more dynamic, and to arouse interest in students. From that, the teachers bring new teaching methodologies for classroom, a great proposal are educational games. Thinking about it, the referring article aims to determine the contributions of the game Show atomic to the students
\end{abstract}

of the 1st series of the night high school School Antonio Dantas in the municipality of Apodi -RN . During implementation, the students interacted more in class, based on a questionnaire, they approved the playful applied and recommended more applications of educational games in the classroom.

KEY-WORDS: Educational games, Atomic structure, Chemistry 


\section{O SHOW ATÔMICO : JOGO DIDÁTICO COMO FERRAMENTA NO PROCESSO DE ENSINO E APRENDIZAGEM DE ESTRUTURA ATÔMICA}

\section{INTRODUÇÃO}

O modelo tradicional de ensino é um dos obstáculos que devem ser superados, visto que é uma atitude comum de muitos professores, utilizarem somente esse recurso para ministrar suas aulas, fazendo com que os alunos aprendam pela memorização e de forma mecânica, não praticando assim, seu senso crítico, sendo somente um receptor de informações. (CASTRO; COSTA, 2011)

Atualmente, é interessante que os docentes de Química percebam que os estudantes vivem em um mundo mais dinâmico com o uso de tecnologias e que façam das suas aulas, aulas dinâmicas também, para que as mesmas não se tornem enfadonhas para os alunos. (TRINDADE, 2011)

Um novo método para resolver essas dificuldades são os jogos didáticos, segundo Mello et al. (2011):

\footnotetext{
"Os jogos ou atividades lúdicas têm o potencial de estimular a interação social e o processo construtivo do educando (participante), possibilitando trocas e compartilhamento de problemas e soluções, de maneira interativa, horizontal e dialógica."
}

Ou seja, os lúdicos podem ser ferramentas para auxiliar para os professores em suas aulas. Partindo desse pressuposto, o referente artigo tem como finalidade avaliar as contribuições do jogo didático "O Show Atômico" para os alunos da 1ạ série do Ensino Médio noturno da Escola Estadual Professor Antônio Dantas.

\section{MATERIAIS E MÉTODOS}

Para a realização do jogo Show Atômico, inicialmente foram feitas pesquisas bibliográficas sobre jogos didáticos, depois com o tema, foram feitas adaptações do mesmo para o conteúdo abordado. Houve a construção do jogo através de slides, cartas e placas. O jogo contém 20 perguntas, sendo que 18 são dividas em 3 etapas: fácil, médio e difícil, além de cada questão ter 5 alternativas, as quais somente uma é a correta. Para as placas e cartas foram utilizados papel ofício e cartolina.

O jogo foi aplicado na turma da 1a série do ensino médio noturno, composta por 13 alunos, visto que os mesmos viram estrutura atômica e o jogo será utilizado para revisar o conteúdo. Para a avalição dessa atividade, foi constrúido um questionário envolvendo o conteúdo abordado e o que os alunos acharam sobre o jogo.

\section{RESULTADOS E DISCUSSÕES}

A sala foi dividida em 2 grupos, e cada grupo teve 2 minutos para responder as perguntas do jogo. Durante o jogo, os alunos mostraram-se muito participativos, porém, obtiveram dificuldades nas questões de cálculo sobre determinação do número de massa e nêutrons, mas nada que atrapalhasse o desenvolvimento do lúdico. 
Figura 1: Os alunos durante a execução do jogo

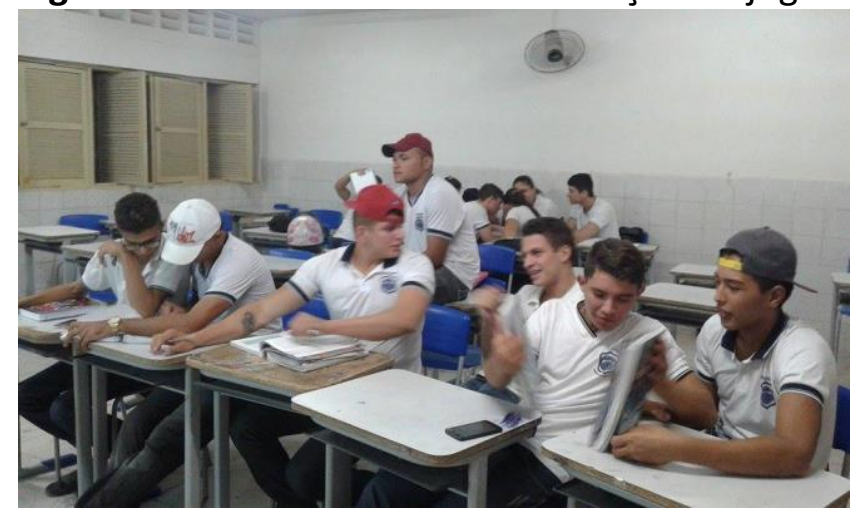

Fonte: Próprio autor

Durante a aplicação do lúdico, os alunos interagiram mais do que interagem normalmente em sala de aula, um exemplo era saber o porquê que determinada questão estava incorreta, aprendendo a corrigir os próprios erros sobre o conteúdo. Essa interação deve-se a ânsia de ganhar, segundo Fialho (2008) "jogando, o indivíduo se depara com o desejo de vencer que provoca uma sensação agradável, pois as competições e os desafios são situações que mechem com nossos impulsos", sendo assim, o alunos buscam saber a resposta e estudam para ganhar o jogo, ao mesmo tempo que aprendem e se interessam pelo assunto.

Após a aplicação da atividade, os alunos responderam um questionário com 5 perguntas objetivas e de acordo com os dados levantados, dos 13 alunos, 11 admitem sentirem dificuldades no assunto de estrutura atômica e com relação ao jogo, a maioria não teve problemas com a execução do lúdico, ou seja, a atividade proposta é simples e fácil de executá-la. Questionados se o lúdico possibilitou mais aprendizado sobre o tema abordado, todos disseram sim e deram nota máxima para o jogo, além de concordarem que deveriam ser aplicados mais jogos em sala de aula, o que reforça o que diz Silva (2012), segundo o mesmo: "São também instrumentos que motivam, atraem e estimulam o processo de construção do conhecimento...". Ou seja, os jogos didáticos permitem momentos também de aprendizagem, e é interessante que o professor traga isso para sua aulas, promovendo mais aprendizado de forma diferenciada e divertida para os alunos.

\section{CONCLUSÃO}

Com base nos dados coletados e na interação dos alunos sobre o jogo, conclui-se, que os jogos didáticos são ferramentas facilitadoras para a processo de ensino e aprendizagem dos mesmos, e que o jogo Show Atômico possibilitou-os aprenderam mais sobre estrutra atômica, além de revisarem os conhecimentos já tidos. Confirmou-se também que através do lúdico aplicado, os alunos interagiram mais em sala de aula, proporcionando um ambiente de maior aprendizado e de forma divertida.

\section{AGRADECIMENTOS}

Os autores agradecem ao Programa Institucional de Bolsas de Iniciação à Docência (PIBID) pela a oportunidade de desenvolvimento do projeto, a Coordenação e Aperfeiçoamento de Pessoas de Ensino Superior (CAPES) pelo financiamento das bolsas, e a Escola Estadual Professor Antônio Dantas (EEPAD) pelo espaço cedido. 


\section{REFERÊNCIAS}

CASTRO, Bruna Jamila de; COSTA, Priscila Caroza Frasson. Contribuições de um jogo didático para o processo de ensino e aprendizagem de Química no Ensino Fundamental segundo o contexto da Aprendizagem Significativa. Revista Electrónica de Investigación En Educación En Ciencias, Buenos Aires, v. 6, n. 2, p.25-37, Julho, 2011. Disponível em: <http://reiec.sites.exa.unicen.edu.ar/>. Acesso em: 15 jul. 2016.

FIALHO, Neusa Nogueira. OS JOGOS PEDAGÓGICOS COMO FERRAMENTAS DE ENSINO. In: EDUCERE, 8., 2008, Curitiba. Anais... . Curitiba: Champagnat, 2008. p. 12299 - 12306.

MELLO, Bruna Luiza Dutra de et al. "Show do Milhão": uma estratégia pedagógica nas atividades de educação em enfermagem. Saúde Coletiva, São Paulo, v. 8, n. 52, p.187190, mar. 2011.

SILVA, Tiago Pereira da. A UTILIZAÇÃO DO JOGO LUDO QUÍMICO COMO INSTRUMENTO MOTIVADOR E FACILITADOR DA APRENDIZAGEM DE CINÉTICA QUÍMICA NA 2a SÉRIE DO ENSINO MÉDIO DO COLÉGIO ESTADUAL PROFESSOR JOSÉ ABDALLA. 2012. 55 f. TCC (Graduação) - Curso de Licenciatura Plena em Química, Universidade Estadual de Goiás Unidade Universitária de Ciências Exatas e Tecnológicas Curso de Química, Anápolis, 2012.

TRINDADE, Letícia Guerreiro de. ABORDAGENS ALTERNATIVAS PARA O ENSINO DE QUÍMICA: ELABORAÇÃO DE MATERIAL DIDÁTICO E AULAS PRÁTICAS. 2011. 57 f. TCC (Graduação) - Curso de Licenciatura Plena em Química, Universidade Federal do Rio Grande do Sul, Porto Alegre, 2011. 